\title{
Investigating Health Service Availability and \\ Readiness for Antenatal Testing and Treatment for HIV and Syphilis in Papua New Guinea
}

\section{Olga PM Saweri ( $\square$ nsaweri@kirby.unsw.edu.au )}

The Kirby Institute, University of New South Wales

\section{Neha Batura}

Institute for Global Health, University College London

Justin Pulford

Liverpool School of Tropical Medicine

\section{M.Mahmud Khan}

University of Georgia

Xiaohui Hou

World Bank

William S Pomat

Papua New Guinea Institute of Medical Research

\section{Andrew J Vallely}

The Kirby Institute, University of New South Wales

\section{Virginia Wiseman}

The Kirby Institute, University of New South Wales

\section{Research Article}

Keywords: health facility readiness, antenatal care, HIV, syphilis, health service assessment, pacific

Posted Date: February 10th, 2022

DOI: https://doi.org/10.21203/rs.3.rs-1281575/v1

License: (1) (1) This work is licensed under a Creative Commons Attribution 4.0 International License. Read Full License 
1 Investigating health service availability and readiness for antenatal testing and treatment

2 for HIV and syphilis in Papua New Guinea

3

4 AUTHORS:

$5 \quad$ Olga PM Saweri ${ }^{1,2^{*}}$

6 Neha Batura ${ }^{3}$

7 Justin Pulford ${ }^{4}$

8 M. Mahmud Khan ${ }^{5}$

9 Xiaohui $\mathrm{Hou}^{6}$

10 William S Pomat ${ }^{1,2}$

11 Andrew J Vallely ${ }^{1,2}$

12 Virginia Wiseman ${ }^{1,7}$

13

14 1. The Kirby Institute, University of New South Wales, Sydney, Australia;

15 2. The Papua New Guinea Institute of Medical Research, Goroka, Papua New Guinea;

16 3. Institute for Global Health, University College London, London, United Kingdom;

17 4. Liverpool School of Tropical Medicine, Liverpool, United Kingdom

18 5. University of Georgia, Athens, United Sates of America 
19 6. The World Bank Group, Washington DC, United States of America

20 7. Department of Global Health and Development, London School of Hygiene and Tropical

21 Medicine, London, United Kingdom.

23 Corresponding author:

24 Email: nsaweri@kirby.unsw.edu.au

\section{Abstract}

27 Background Papua New Guinea (PNG) has one of the highest burdens of HIV and syphilis in pregnancy in the Asia-Pacific region. Timely and effective diagnosis can alleviate the burden of HIV and syphilis and improve maternal and newborn health. Supply-side factors related to

30 implementation and scale up remain problematic, yet few studies have considered their impact

31 on antenatal testing and treatment for HIV and syphilis. This study explores health service availability and readiness for antenatal HIV and/or syphilis testing and treatment in PNG.

Methods Using data from two sources, we demonstrate health service availability and

34 readiness. Service availability is measured at a province level as the average of three indicators:

35 infrastructure, workforce, and antenatal clinic utilization. The readiness score comprises 28 equally weighted indicators across four domains; and is estimated for 73 health facilities.

37 Bivariate and multivariate robust linear regressions explore associations between health facility readiness and the proportion of antenatal clinic attendees tested and treated for HIV and/or syphilis. 
40 Results Most provinces had fewer than one health facility per 10000 population. On average, 41 health worker density was 11 health workers per 10000 population per province, and 42 approximately $22 \%$ of pregnant women attended four or more antenatal clinics. Most health 43 facilities had a composite readiness score between $51 \%$ and $75 \%$, with urban health facilities 44 faring better than rural ones. The multivariate regression analysis, when controlling for managing authority, catchment population, the number of clinicians employed, health facility type and residence (urban/rural) indicated a weak positive relationship between health facility

47 readiness and the proportion of antenatal clinic attendees tested and treated for HIV and/or 48 syphilis.

49 Conclusion This study adds to the limited evidence base for the Pacific region. There is a need to improve antenatal testing and treatment coverage for HIV and syphilis and reduce healthcare inequalities faced by rural and urban communities. Shortages of skilled health workers, tests,

52 and medicines impede the provision of quality antenatal care. Improving service availability 53 and health facility readiness are key to ensuring the effective provision of antenatal care 54 interventions.

56 Keywords: health facility readiness, antenatal care, HIV, syphilis, health service assessment, 57 pacific 


\section{Background}

60 Sexually transmitted infections (STIs) are associated with adverse pregnancy and birth outcomes including miscarriage, preterm birth, low birthweight, stillbirth, and neonatal death [1-11]. Globally, 1.4 million pregnant women are diagnosed with HIV, and 988000 with syphilis annually; most infections occur in low- and middle- income countries (LMICs) [12]. Papua New Guinea (PNG) has one of the highest burdens of HIV and syphilis in the AsiaPacific region [13]. Studies indicate that approximately half of all pregnant women in PNG are infected with not just one, but multiple STIs, including HIV and syphilis [14].

Timely and effective diagnosis and treatment can help alleviate the high burden of STIs among pregnant women $[14,15]$. Implementation and scale-up of these interventions remain a major challenge for many LMICs. For HIV and syphilis, the introduction of serological single-use point-of-care test kits has made timely and accurate detection feasible, and is a widely accepted part of routine antenatal care (ANC) [16]. Many LMICs, including PNG, have integrated HIV and syphilis testing and treatment into routine ANC. However, there is a growing body of evidence highlighting significant structural barriers to delivering these services at scale [17], such as a lack of diagnostics, medicines, an inadequate number and mix of skilled health workers, deteriorating health facility infrastructure, and financing or budgetary constraints [1820]. These barriers can hinder the provision of quality ANC in LMIC, including the consistent testing and appropriate treatment for HIV and syphilis in pregnancy [21-24].

HIV and syphilis testing have been part of routine ANC in PNG for over 10 years [16, 25]. A national health indicator surveillance report estimated that approximately $51.3 \%$ of antenatal clinic attendees were tested for HIV in 2019 [26] and 44.2\% for syphilis in 2018 [27]. Further,

81 HIV and syphilis prevalence in pregnancy in 2019 was $1.6 \%$ and 4\% respectively [28], resulting in the persistent occurrence of adverse pregnancy and birth outcomes $[26,29]$. Over

83 the last decade, there has been little to no change in antenatal testing coverage for HIV and 
syphilis in PNG, which has indirectly affected treatment rates [26, 29]. As a result, the government of PNG has set a national target for antenatal testing and treatment for HIV and syphilis coverage, which is $90 \%$ of antenatal attendees by 2030 [26].

87 Timely and appropriate testing and treatment of HIV and syphilis at scale requires the availability of appropriate human and capital resources to provide quality health services, meet national coverage targets, and achieve better health outcomes. It has become increasingly common to use tools such as the Service Availability and Readiness Assessment (SARA) survey [30] to identify gaps in service delivery. In this study, we adapted the SARA survey to identify gaps in health service availability and health facility readiness for antenatal testing and treatment for HIV and syphilis in PNG. Associations between health facility readiness and antenatal testing and treatment of HIV and syphilis in PNG were also explored. To our knowledge, this is the first study of its kind, using nationally representative survey data, in the

96 Pacific region.

\section{Methods}

\section{$98 \quad$ Study setting}

99 PNG has a population of more than 8 million people, $85 \%$ of whom live in rural areas [31].

100 Administratively, PNG is divided into 22 provinces across four geographical regions, namely 101 Momase, Highlands, Southern and the New Guinea Islands. Public healthcare is decentralised 102 and funded through budgetary allocations from the national and provincial governments, donor 103 agencies, non-governmental organizations, church-groups and private service providers [32].

104 Health facilities in PNG are categorised hierarchically according to size and clinical capability.

105 Health services are decentralised by province, where There are seven levels, and each level is 106 defined by a set of minimum standards, such as staff ceilings and service provision [33]. Levels 
107 1-4 focus on primary health care whilst levels 5-7 provide secondary healthcare in addition to

108 primary health care. Table 1 summarises the key characteristics of health facilities at each level.

109 Table 1: Health facility characteristics by type of health facility

\begin{tabular}{|c|c|c|c|c|}
\hline Health facility type & $\begin{array}{l}\text { Number } \\
\text { of health } \\
\text { facilities }\end{array}$ & $\begin{array}{c}\text { Average } \\
\text { number } \\
\text { of health } \\
\text { workers }^{b}\end{array}$ & $\begin{array}{l}\text { Average } \\
\text { number } \\
\text { of beds }\end{array}$ & $\begin{array}{c}\text { Average catchment } \\
\text { population [32] }\end{array}$ \\
\hline \multicolumn{5}{|c|}{ Primary Healthcare (levels 1-4) } \\
\hline $\begin{array}{l}\text { Community Health } \\
\text { Posts }\end{array}$ & $3088^{d}$ & $\begin{array}{l}3 \\
(2)\end{array}$ & 1.9 & $500-2000$ \\
\hline $\begin{array}{l}\text { Sub-Health Centers } \\
\text { and Urban Clinics }\end{array}$ & $458^{\mathrm{d}}$ & $\begin{array}{l}6.4 \\
(4)\end{array}$ & 5.4 & $\begin{array}{l}2000-5000 \text { (rural population) } \\
>10000 \text { (urban population) }\end{array}$ \\
\hline Health Centers & $261^{\mathrm{d}}$ & $\begin{array}{l}11 \\
(7)\end{array}$ & 16.5 & $5000-10000$ \\
\hline $\begin{array}{l}\text { District/Rural } \\
\text { Hospitals }\end{array}$ & 14 & $\begin{array}{c}39.5 \\
(14-35)\end{array}$ & 61.3 & $>70000$ \\
\hline
\end{tabular}

\begin{tabular}{|c|c|c|c|c|}
\hline \multicolumn{5}{|c|}{ Secondary Healthcare (levels 5-7) } \\
\hline $\begin{array}{l}\text { Provincial/ } \\
\text { Regional/ National } \\
\text { Referral Hospitals }\end{array}$ & $21^{\mathrm{e}}$ & $\begin{array}{c}176 \\
(63-355)\end{array}$ & 78.8 & 100000 - total population \\
\hline a. $\quad$ Source: [34] & & & & \\
\hline \multicolumn{5}{|c|}{$\begin{array}{l}\text { b. Indicates the observed average number of health workers, and in parentheses are the number of mandated health } \\
\text { workers according to National Health Service Standards. Source:[32] }\end{array}$} \\
\hline \multirow{2}{*}{\multicolumn{5}{|c|}{$\begin{array}{l}\text { c. Source: [27] } \\
\text { d. Not all health facilities are onen (onerational) or staffed }\end{array}$}} \\
\hline $\begin{array}{ll}\text { d. } & \text { Not all health facilities are open (operational) or staffed } \\
\text { e. } & \text { Includes seventeen provincial hospitals, three regional hospitals, and one national referral hospital }\end{array}$ & & & & \\
\hline
\end{tabular}

\section{Data Sources}

111 Data from two sources were used for the analysis. The first source was the national health

112 indicator surveillance (NHIS) system [27], retrieved from the National Department of Health

$113(\mathrm{NDoH})$ in September 2020. The NHIS is a monitoring and surveillance instrument showcasing

114 year-on-year progress towards health sector medium- and long-term targets $[25,35]$. Privately

115 owned/managed health facilities and pharmacy-based clinics are not part of the NHIS dataset,

116 and therefore not included in this study [30]. We used data collected from 813 health facilities

117 in 2015 to ensure compatibility with the second data source (described below). From the NIHS 
118 dataset, we obtained the number of health facilities per province, the size of the provincial

119 health workforce, antenatal clinic attendance or utilization per province, the number of

120 antenatal clinic attendees tested for HIV and syphilis per health facility, and the seropositive

121 antenatal clinic attendees treated for HIV per health facility. Data for the number of

122 seropositive antenatal clinic attendees treated for syphilis per health facility was not available,

123 and therefore not included in this analysis.

124 The second data source was a national health facility efficiency survey completed in 2015 [36].

125 The survey was jointly funded by the NDoH, the Australian Department of Foreign Affairs and

126 Trade (DFAT) and the World Bank and carried out by the Arnold School of Public Health of

127 the University of South Carolina, the Nossal Institute of Public Health of the University of

128 Melbourne, and the PNG Institute of Medical Research. The survey was undertaken in 73

129 public and church-run health facilities. The sample included all publicly run hospitals (level 5-

1307 health facilities) and a random selection of level 3-4 health facilities in 13 provinces, which

131 were stratified by district. A more detailed explanation of the study design can be obtained

132 from the survey's full report [36]. Data on health facility amenities, infection prevention

133 protocols, and the availability of diagnostic equipment, medicines and medical supplies was

134 extracted from this dataset to calculate health facility readiness scores. 


\section{Defining key variables}

136 Service availability demonstrates the physical presence of health services across a country's

137 health system [22, 30]. According to the World Health Organization's (WHO) SARA toolkit,

138 service availability is measured by three indicators related to infrastructure, health workers and

139 health service utilisation [30], which we extracted from the NHIS [27]:

140 a) Density of health facilities: the number of operational health facilities per 10000

141 population by province. This includes all public and church-run health facilities

$142 \quad(\mathrm{~N}=813)$ reported in the NHIS.

143 b) Density of core health workers: the number of core health workers per 10000

144 population by province. This includes all clinician cadres, namely medical officers

145 (doctors), health extension officers (HEOs) ${ }^{1}$, nurses, midwives, and community health

$146 \quad$ workers $(\mathrm{CHWs})^{2}$.

147 c) Antenatal clinic utilization: the percentage of pregnant women making four or more

148 visits to an antenatal clinic, by province. This is based on the number of births and

149 stillbirths reported as a proxy for the number of pregnant women (measure used by the

$150 \quad \mathrm{NDoH}[35])$.

151 Health facility readiness is measured by the factors related to a health facility's capacity to

152 provide healthcare [22, 30]. Adopting the approach used by Leslie et al. (2017) [37], we

153 created a health facility readiness score for each facility that comprised four domains:

154 amenities; protocols for infection prevention; diagnostic equipment; and medicines and

155 medical supplies Each domain includes multiple indicators (see Table 2). The choice of

156 indicators for each domain was guided by the SARA toolkit [30] and adapted to the PNG

\footnotetext{
${ }^{1}$ Health Extension Officers (HEOs) are universally comparable to physician assistant.

${ }^{2}$ Community Health Workers (CHWs) are universally comparable to nurse aids.
} 
$158 \quad$ 'statistical analysis'.

\section{Statistical analysis}

161 The service availability score is the average of three indicators: infrastructure; workforce; and

162 antenatal clinic utilization, and is expressed as a percentage [30]. Each indicator is calculated

163 at the province level and calculated using the following equations.

164 Infrastructure: density of health facilities per 10000 population (shown by province);

165 compared to the global WHO target of 2 health facilities per 10000 population [30].

$$
\underset{\text { Infrastructure }}{\text { Provincial }}=\left(\left(\frac{\text { Number of Open Health Facilities }}{\text { (Population } \div 10000)}\right) / \text { WHO Target }\right) \times 100 \%
$$

166

167 Workforce: density of core health workers per 10000 population (shown by province);

168 compared to the global WHO target of 23 health workers per 10000 population [30].

$$
\underset{\text { Provincial }}{\text { Workforce }}=\left(\left(\frac{\text { Number of Core Health Workers }}{(\text { Population } \div 10000)}\right) / \text { WHO Target }\right) \times 100 \%
$$

169

170 Antenatal clinic utilization: proportion of pregnant women making at least 4 antenatal clinic

171 visits per province [38]. Antenatal clinic utilization is compared to the global target of all

172 pregnant women having at least 4 antenatal clinic visits per province [39]. The WHO now

173 recommends at least 8 antenatal clinic visits per pregnancy [38]; however, this study utilises

174 the target of at least 4 antenatal clinic visits per pregnancy as per national policy [25].

$$
\underset{\text { ANC Utilization }}{\text { Provincial }}=\left(\frac{\text { No. Pregnant Women Accessing ANC at Least } 4 \text { Times }}{\text { No. of Pregnant Women }}\right) \times 100 \%
$$


176 Service availability is the average of Equations 1, 2, and 3:

$$
\text { Service Availability }(\%)=\frac{(\text { Infrastructure }+ \text { Workforce }+ \text { ANC utilization })}{3}
$$

178 Health facility readiness is a composite score comprising 28 indicators across four domains

179 (Table 2). Each indicator is dichotomous with a value of 0 demonstrating the indicator is not

180 available and a value of 1 indicating it is available, multiplied by the domain weight and

181 presented as a percentage. We initially used principal component analysis (PCA) to determine

182 data-derived weights and construct readiness scores. To demonstrate the sample's suitability

183 for a PCA, we ran a Kaiser-Meyer-Olkin (KMO) test for sampling adequacy. The KMO test

184 indicates whether there is sufficient correlation within a sample to conduct a PCA or factor

185 analysis $[40,41]$. A KMO score greater than 0.5 suggests that the variables within a sample are

186 highly correlated and justifies the use of PCA [41-43]. The KMO score for this sample was

1870.3 , thus the use of the PCA was not justified. Given this, equal weights were attached to each

188 domain and to each indicator across the four domains. The use of equal weights is common

189 practice in health readiness analyses [18, 30, 37, 44, 45]. A score of 100 indicates that a health

190 facility has all the necessary components to effectively test and treat antenatal clinic attendees

191 for HIV and syphilis at point-of-care. The equation is shown below:

$$
\left.\underset{\text { score }}{\text { Readiness }}=(0.25 \text { (amenities) })+0.25\left(\begin{array}{c}
\text { infection } \\
\text { prevention }
\end{array}\right)+0.25\left(\begin{array}{c}
\text { antenatal } \\
\text { equipment }
\end{array}\right)+0.25\left(\begin{array}{c}
\text { antenatal } \\
\text { medicines }
\end{array}\right)\right) \times 100 \%
$$

192 In the linear regression, data from 73 facilities surveyed were used to assess the association

193 between testing and treating HIV and syphilis in an antenatal clinic with health facility

194 readiness. The main dependent variables were:

(a) Proportion of antenatal clinic attendees tested for HIV; 
(b) Proportion of seropositive antenatal clinic attendees treated for HIV; and

(c) Proportion of antenatal clinic attendees tested for syphilis.

Independent variables included in the regression analysis were selected based on the published

199 literature $[18,37,44]$ and available data at the health facility level:

(a) Health facility type: classification of a health facility as a health centre, district hospital or a provincial hospital;

(b) Health facility residence: located in either a rural or an urban setting;

(c) Managing authority: public- or church -run health facilities;

(d) Catchment population: identified by a health facility as the population it serves; and

(e) Clinicians employed: the number of medical officers, nursing officers, HEOs and

For the bivariate analysis, the proportion of antenatal clinic attendees tested for HIV was (equation 6a). Thereafter, conditional on antenatal clinic attendees being tested for HIV, we

6b). The equations were:

$$
\begin{gathered}
\text { proportion of } \\
\text { antenatal clinic }
\end{gathered}=\beta_{0}+\beta_{1}\left(\begin{array}{c}
\text { health facility } \\
\text { readiness } \\
\text { score }
\end{array}\right)+U
$$

$$
\begin{gathered}
\text { proportion of HIV } \\
\text { seropositive antenatal clinic } \\
\text { attendees treated }
\end{gathered}=\beta_{0}+\beta_{1}\left(\begin{array}{c}
\text { health facility } \\
\text { readiness } \\
\text { score }
\end{array}\right)+U
$$

213 Due to a lack of treatment data for syphilis, it was only possible to explore the association

214 between the proportion of antenatal clinic attendees tested for syphilis and health facility

215 readiness (equation 7). The regression equation for syphilis was: 


$$
\begin{gathered}
\text { proportion of } \\
\text { antenatal clinic attendees } \\
\text { tested for syphilis }
\end{gathered}=\beta_{0}+\beta_{1}\left(\begin{array}{c}
\text { health facility } \\
\text { readiness } \\
\text { score }
\end{array}\right)+U
$$

216 In the multivariate analysis, all dependent variables were continuous, while the independent

217 variables were both continuous and categorical. The health facility readiness score, the number

218 of clinicians employed (on a logarithmic scale) were continuous, while health facility residence

219 (urban or rural), type of health facility, management of the health facility (public- or church-

220 run), and catchment population were all categorical. When fitting the model, the 'residence'

221 variable was excluded due to collinearity. We used $\mathrm{P}<0.05$ to determine statistical significance.

222 The linear regression equations, with robust standard errors for testing HIV (equation 8a) and

223 treating seropositives for HIV (equation 8b) were as follows:

$$
\begin{aligned}
\begin{array}{c}
\text { proportion of } \\
\text { antenatal clinic attendees }=\beta_{0}
\end{array} & +\beta_{1}\left(\begin{array}{c}
\text { health facility } \\
\text { readiness } \\
\text { score }
\end{array}\right)+\beta_{2}\left(\begin{array}{c}
\text { management } \\
\text { authority }
\end{array}\right)+\beta_{3}\left(\begin{array}{c}
\text { health } \\
\text { facility } \\
\text { type }
\end{array}\right) \\
& +\beta_{4}\left(\begin{array}{c}
\log \text { clinicians } \\
\text { employed }
\end{array}\right)+\beta_{5}\left(\begin{array}{c}
\text { catchment } \\
\text { population }
\end{array}\right)+U
\end{aligned}
$$

$$
\begin{aligned}
& \begin{array}{l}
\text { proportion of HIV } \\
\text { attendees treated }
\end{array} \text { ositive antenatal clinic }=\beta_{0}+\beta_{1}\left(\begin{array}{c}
\text { health facility } \\
\text { readiness } \\
\text { score }
\end{array}\right)+\beta_{2}\left(\begin{array}{c}
\text { management } \\
\text { authority }
\end{array}\right)+\beta_{3}\left(\begin{array}{c}
\text { health } \\
\text { facility } \\
\text { type }
\end{array}\right) \\
& +\beta_{4}\left(\log \begin{array}{c}
\text { clinicians } \\
\text { employed }
\end{array}\right)+\beta_{5}\left(\begin{array}{c}
\text { catchment } \\
\text { population }
\end{array}\right)+U
\end{aligned}
$$

The regression equation for syphilis (equation 9) was as follows:

$$
\begin{aligned}
& \begin{array}{c}
\text { proportion of } \\
\text { antenatal clinic attendees } \\
\text { tested for syphilis }
\end{array}=\beta_{0}+\beta_{1}\left(\begin{array}{c}
\text { health facility } \\
\text { readiness } \\
\text { score }
\end{array}\right)+\beta_{2}\left(\begin{array}{c}
\text { management } \\
\text { authority }
\end{array}\right)+\beta_{3}\left(\begin{array}{c}
\text { health } \\
\text { facility } \\
\text { type }
\end{array}\right) \\
& +\beta_{4}\left(\log \begin{array}{c}
\text { clinicians } \\
\text { employed }
\end{array}\right)+\beta_{5}\left(\begin{array}{c}
\text { catchment } \\
\text { population }
\end{array}\right)+U
\end{aligned}
$$

227 All statistical analyses were carried out using Microsoft Excel version 365 (Microsoft Corp) and Stata version 13 (Stata Corp). 
230 All 73 health facilities in the sample provided ANC services and were included in this analysis.

231 Table 3 provides a summary of health facilities and service statistics. Most health facilities 232 included in this sample were health centres (64.4\%) and located in rural areas. All hospitals

233 were in urban townships, or provincial towns. Most health facilities in this sample were public

234 health facilities (64.4\%). All hospitals were publicly run, while just under half of the district 235 hospitals and health centres were church run (48\%). Antenatal HIV testing coverage was lower 236 in urban health facilities (5.6\%) compared to rural health facilities $(23.5 \%)$, while HIV 237 treatment coverage was lower in rural health facilities (1.1\%) relative to urban health facilities 238 (4.2\%). The average proportion of antenatal clinic attendees tested for syphilis was higher in 239 urban health facilities $(11.1 \%)$ relative to rural health facilities $(4.3 \%)$.

$240 \quad$ Insert table 3 here

\section{Service Availability}

242 Figure 1 demonstrated that only one province, Manus, achieved the WHO health facility 243 density target. Most provinces (14 out of 22 or 63.6\%) had fewer than one health facility per 24410000 population. The two provinces with the lowest density of open health facilities were the

245 National Capital District and Eastern Highlands Province, both had 0.5 open health facilities 246 per 10000 population. 
247 Figure 1: Infrastructure - Density of health facilities per province in PNG

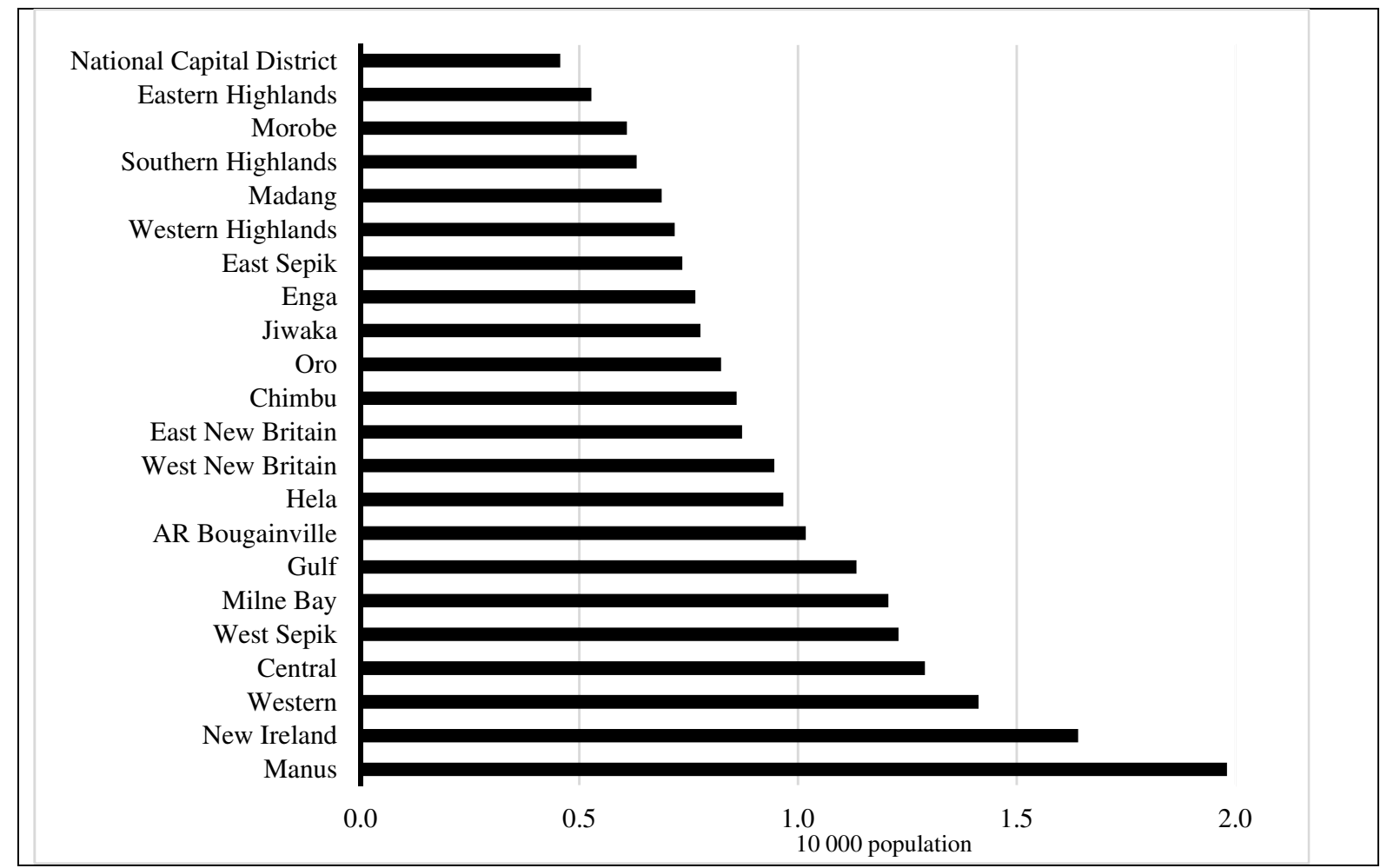

AR Bougainville: Autonomous Region of Bougainville

249 Figure 2 showed that only 3 of $22(13.6 \%)$ provinces, the National Capital District, Milne Bay

250 and Manus, met the health worker density target. In every province, the bulk of the healthcare

251 workforce was made up of nurses, midwives, and CHWs. On average, there was less than one

252 medical officer per 10000 population per province; the largest share of medical officers work

253 in the nation's capital which had on average 5.6 medical officers per 10000 population. Central

254 province and Jiwaka did not report any medical officers employed. 


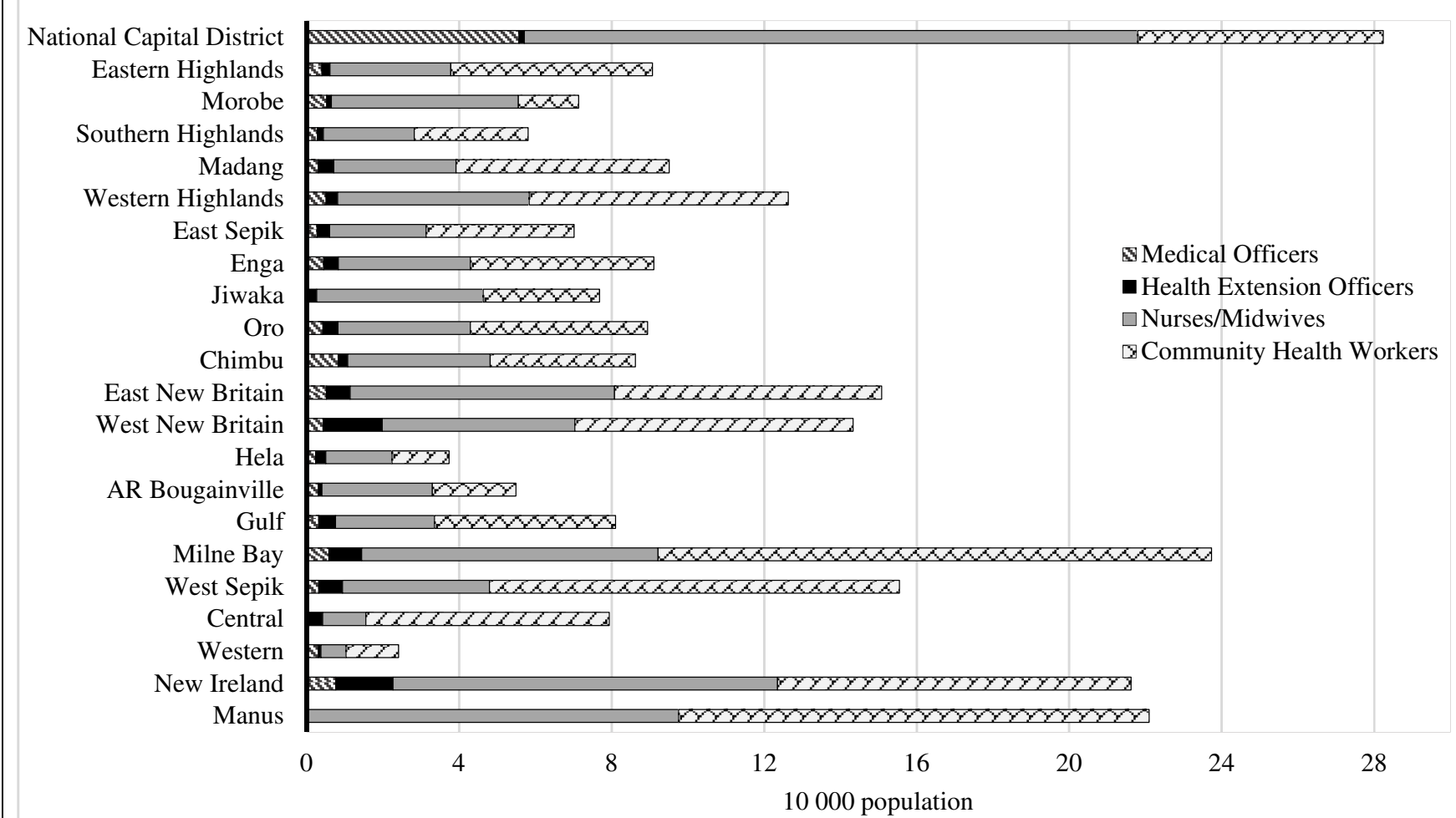

AR Bougainville: Autonomous Region of Bougainville

257 Figure 3 demonstrated that on average, 22\% of pregnant women attended four or more 258 antenatal clinics in 2015. No provinces met the target of all pregnant women attending four or 259 more antenatal clinics. Further, 11 of $22(50 \%)$ provinces had fewer than $20 \%$ of pregnant

260 women attending at least four antenatal clinics throughout pregnancy. ANC utilization was

261 highest in Manus, where about $46 \%$ of pregnant women attended at least four antenatal clinics 262 throughout pregnancy. 

antenatal clinic visits per province in PNG

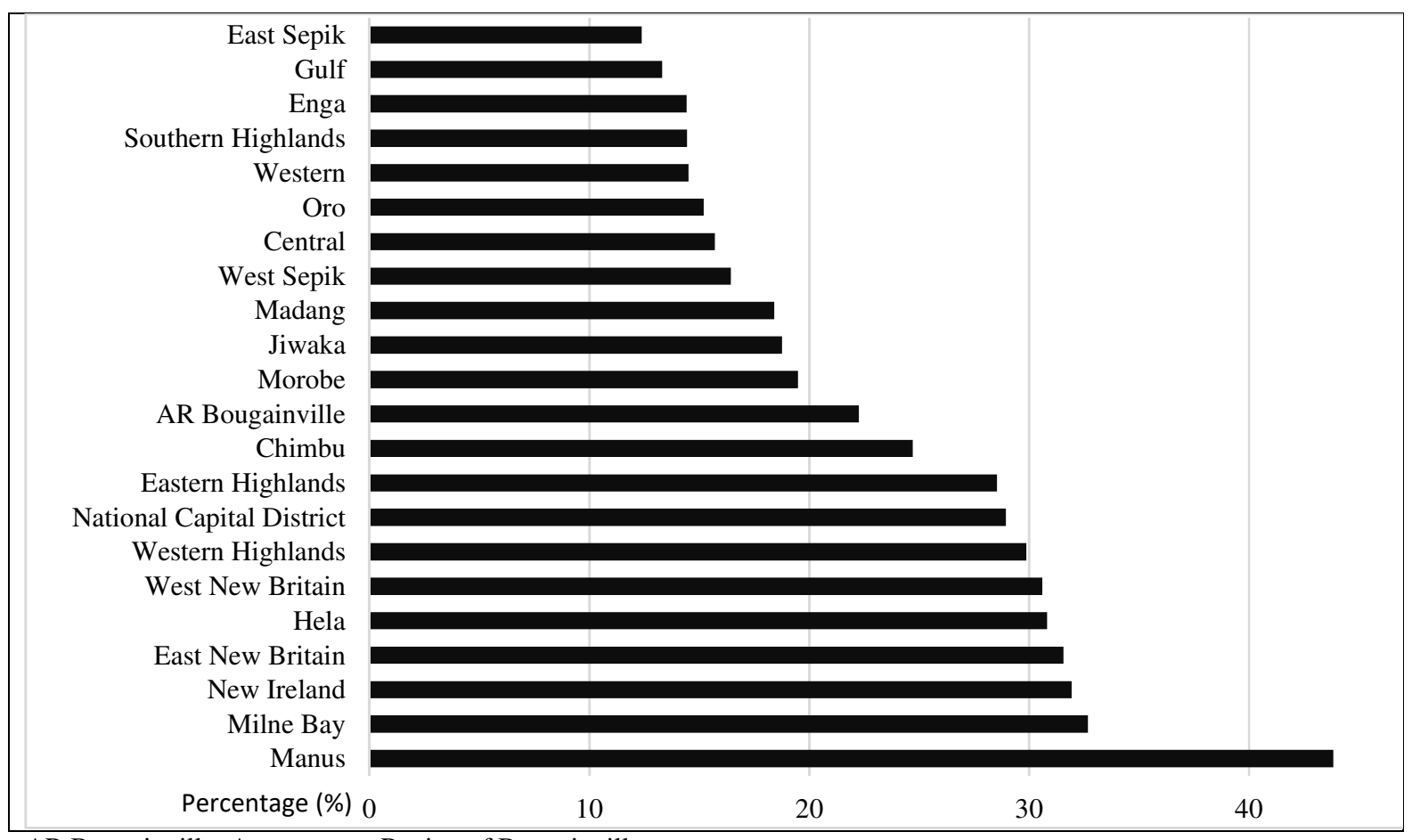

AR Bougainville: Autonomous Region of Bougainville

266 Only 4 out of 22 provinces had a service availability score above 50\% (Figure 4). Service

267 availability ranged from $24 \%$ in the Southern Highlands to $81 \%$ in Manus, the national average

268 was $40 \%$. Further, 12 of $22(55 \%)$ provinces, had a service availability score between 30 and $40 \%$. 


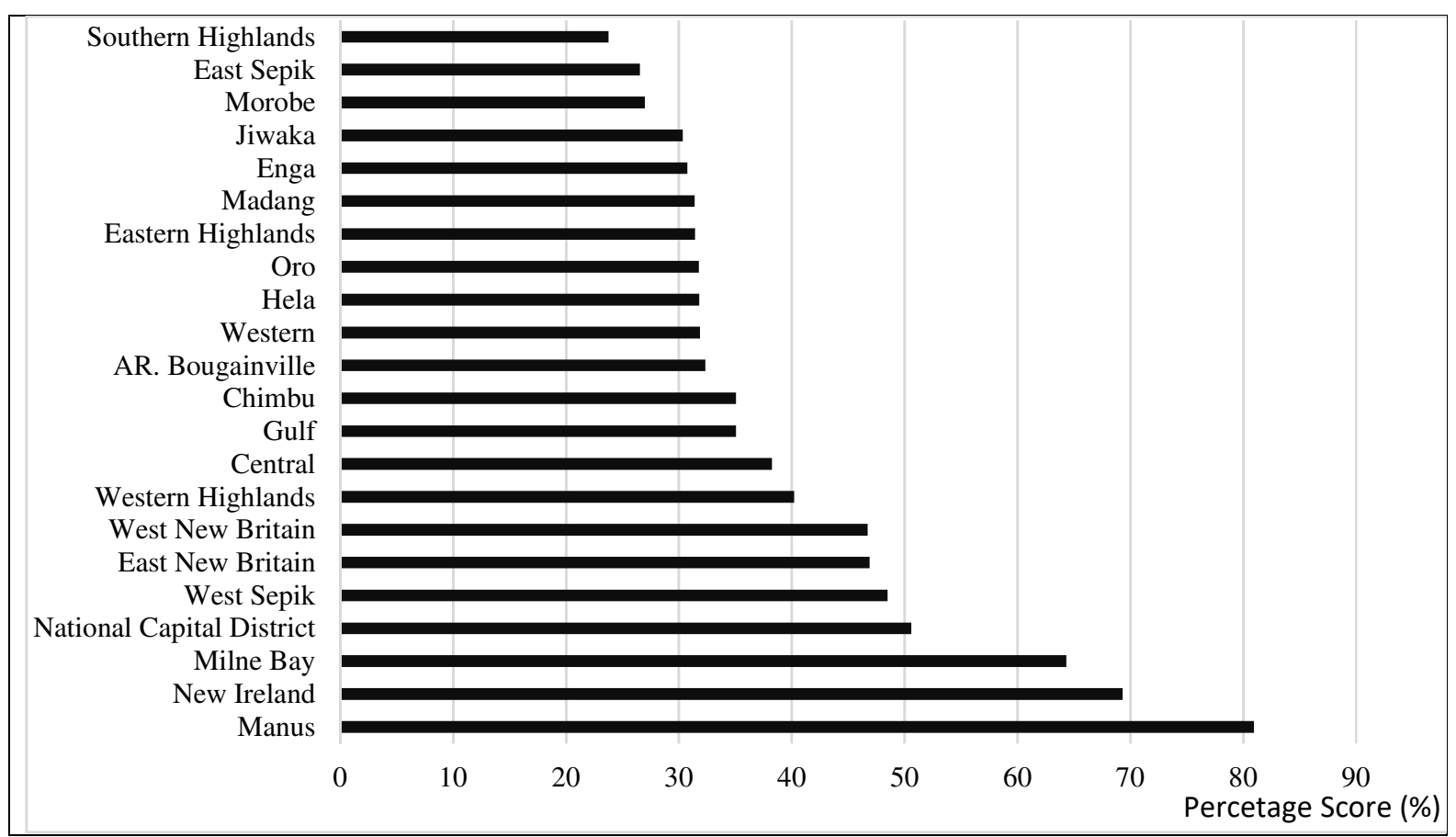

AR Bougainville: Autonomous Region of Bougainville

\section{Health Facility Readiness}

273 Average health facility readiness was 66\%, and most health facilities scored between 51 and

$27475 \%$. Figure 5 illustrates the availability of indicators that make up the readiness score

275 segregated by rural and urban health facilities. With respect to amenities, nearly all health

276 facilities reported having running water (piped directly into the health facility by local

277 authorities or a water tank reliant on rain collection) and emergency transport. Not all health

278 facilities had functioning toilets (61\% of rural health facilities and $84 \%$ of urban). Only $30 \%$

279 of rural health facilities were connected to the main power grid, compared to $90 \%$ of urban

280 health facilities. However, 61\% rural facilities had a generator and 33\% fuel for a generator,

281 which facilitates electricity supply in these areas. All facilities had capacity for infection

282 prevention, and disposed of waste appropriately, either by burning and/or burying, using an

283 incinerator, or disposing off-site. Diagnostic equipment across all facilities, including test kits

284 for protein and glucose and point-of-care test kits for HIV and syphilis, were less likely to be 
285 available in rural health facilities compared to urban ones. Lastly, with respect to the

286 availability of drugs, the treatment for HIV and syphilis, ART and benzathine penicillin

287 respectively, were not adequately supplied across all health facilities sampled (Figure 5).

288 Figure 5: Health facility readiness: Indicators present at all sampled health facilities

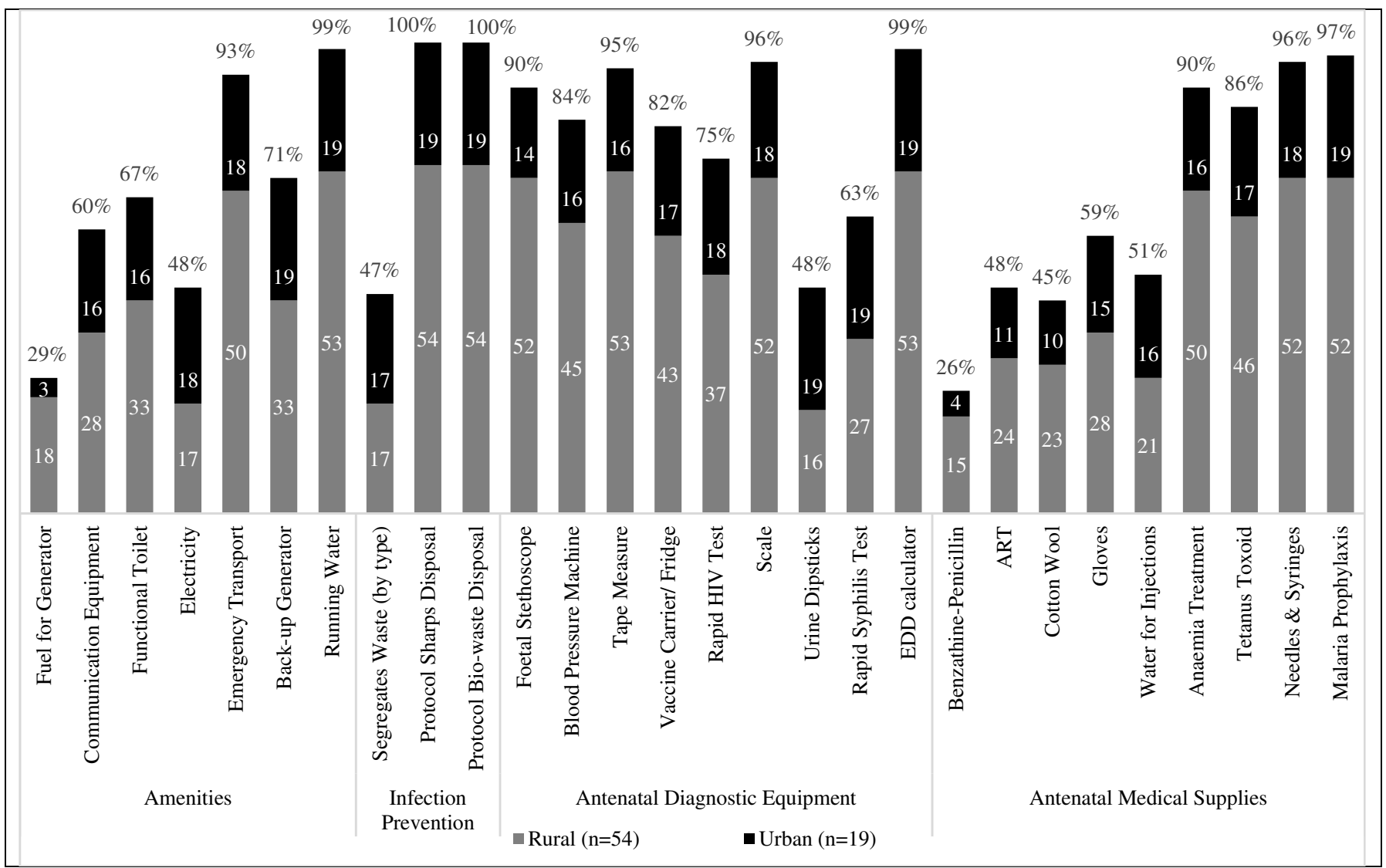

* Numbers presented in each column represent the number of health facilities. Percentages at the top of the columns indicate the percentage of sampled health facilities with the indicator present.

290 Figure 6 illustrates health facility readiness per province. Average health facility readiness for

291 urban health facilities was $77 \%$, while for rural health facilities it was $62 \%$. All health facilities

292 scored above 50\%, although none achieved a score of $100 \%$. In general, urban health facilities

293 had a greater capacity to provide antenatal point-of-care testing and treatment for HIV and

294 syphilis compared to rural ones. 
Figure 6: Health facility readiness (expressed as a percentage score) by province

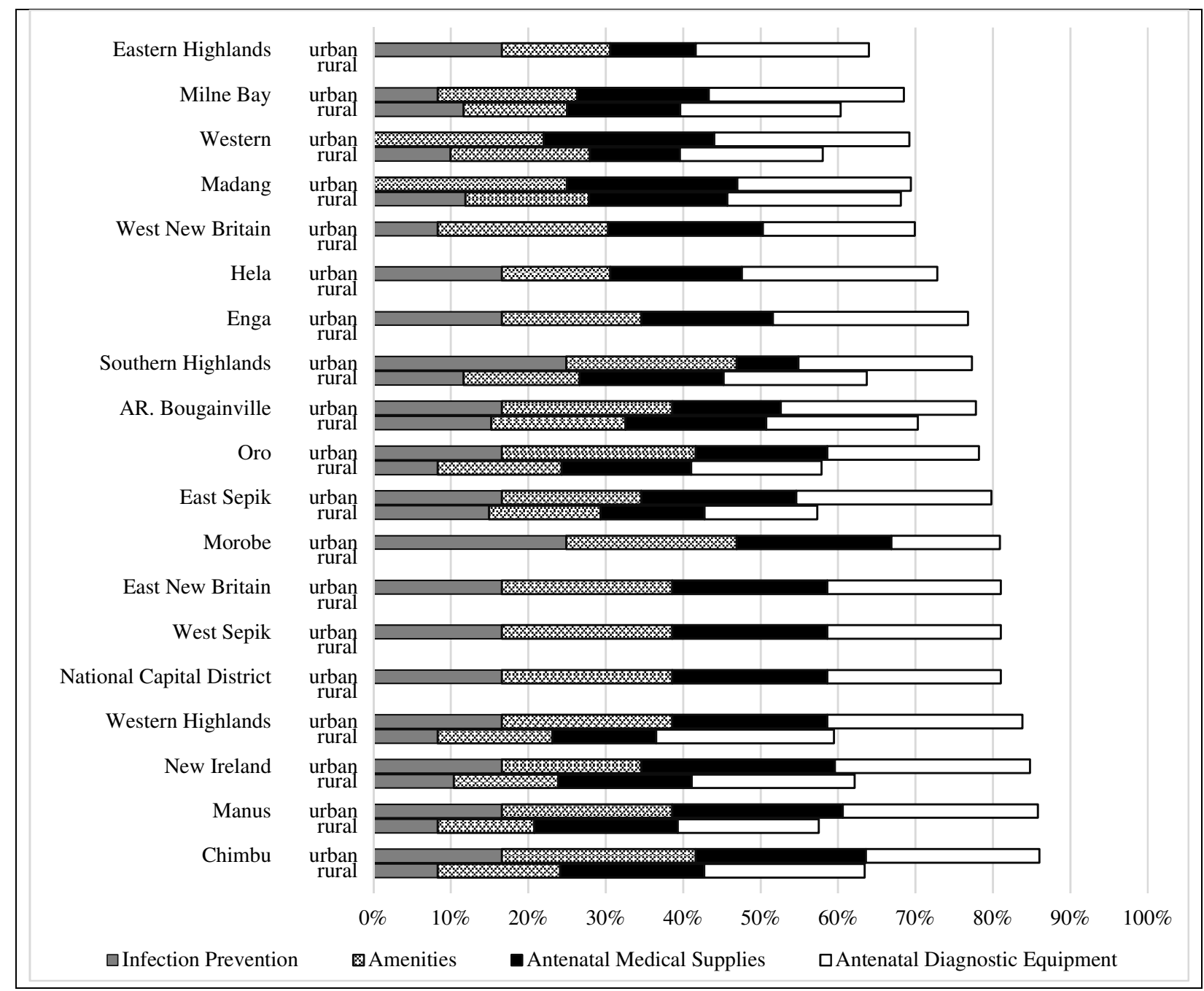

Readiness scores not available for Central, Gulf and Jiwaka; as during the time of the survey, these provinces did not have a level 5 hospital. AR Bougainville: Autonomous Region of Bougainville

\section{Regression analysis}

296 Table 4 presents the results of the bivariate robust linear regressions. There were positive

297 relationships between health facility readiness and the proportion of antenatal clinic attendees

298 tested and treated for HIV, as well as the proportion of antenatal clinic attendees tested for

299 syphilis. However, only the relationship between the proportion of antenatal clinic attendees

300 tested for syphilis and health facility readiness was found to be significant ( $\mathrm{p}$-value $=0.05$ ). 
Table 4: Bivariate association between health facility readiness and the proportion of antenatal clinic attendees tested and treated for HIV and Syphilis

Proportion of antenatal clinic attendees tested for HIV ${ }^{\text {a }}$

\begin{tabular}{lccc}
\hline & Coefficient [95\% CI] & t & P> $|\mathbf{t}|$ \\
\hline Supply-side readiness score & $12.78[-34.11-59.67]$ & 0.54 & 0.589
\end{tabular}

Proportion of HIV seropositive antenatal clinic attendees treated ${ }^{\mathrm{b}}$

\begin{tabular}{lccc}
\hline & Coefficient [95\% CI] & $\mathbf{t}$ & $\mathbf{P}>|\mathbf{t}|$ \\
\hline Supply-side readiness score & $10.25[-1.44-21.95]$ & 1.75 & 0.085
\end{tabular}

Proportion of antenatal clinic attendees tested for Syphilis ${ }^{\mathrm{c}}$

\begin{tabular}{lccc}
\hline & Coefficient [95\% CI] & $\mathbf{t}$ & P> |t $\mid$ \\
\hline Supply-side readiness score & 22.7140 [-0.73-46.14] & 1.93 & 0.057 \\
\hline a. Tested for HIV: Number of observations: 73; R-squared: 0.0042; Prob>F: 0.5885; RMSE: 26.196 & \\
b. Treated for HIV: Number of observations: 73; R-squared: 0.0276; Prob>F: 0.085; RMSE: 8.1432 \\
c. Tested for Syphilis: Number of observations: 73; R-squared: 0.0563; Prob>F: 0.0573; RMSE: 12.433 \\
CI: Confidence Interval; P> |t|: P-value of t-statistic; Prob>F: probability of F statistic; RMSE: Root Mean Square Error; t: t-statistic
\end{tabular}

304 Table 5 presents the results of all three multivariate regressions. Health facility readiness was

305 not associated with antenatal testing and treatment for HIV or antenatal testing for syphilis (p-

306 value $=0.05)$. However, the size of the catchment population was shown to be strongly

307 associated with antenatal HIV and syphilis testing, while health facility was only strongly

308 associated with HIV testing 


\begin{tabular}{|c|c|c|c|c|c|c|c|c|c|}
\hline \multirow[t]{2}{*}{ Variable } & \multicolumn{3}{|c|}{ Tested for HIV ${ }^{a}$} & \multicolumn{3}{|c|}{ HIV seropositives treated ${ }^{b}$} & \multicolumn{3}{|c|}{ Tested for Syphilis $^{c}$} \\
\hline & Coefficient $[95 \% \mathrm{CI}]$ & $\mathbf{t}$ & $\mathbf{P}>|\mathbf{t}|$ & Coefficient $[95 \% \mathrm{CI}]$ & $\mathbf{t}$ & $\mathbf{P}>|\mathbf{t}|$ & Coefficient $[95 \% \mathrm{CI}]$ & $\mathbf{t}$ & $\mathbf{P}>|\mathbf{t}|$ \\
\hline Readiness score & $29.59[-27.88-87.06]$ & 1.03 & 0.307 & $-3.12[-22.86-16.62]$ & -0.32 & 0.753 & $-0.26[-17.47-16.94]$ & -0.03 & 0.976 \\
\hline \multicolumn{10}{|l|}{ Health facility type } \\
\hline Hospital & \multicolumn{9}{|c|}{ Reference Category } \\
\hline District/rural hospital & $35.05[-5.62-75.73]$ & 1.72 & 0.090 & $-0.67[-10.35-9.00]$ & -0.14 & 0.890 & $2.17[-11.32-15.67]$ & 0.32 & 0.749 \\
\hline Health centre & $24.38[1.75-47.02]$ & 2.15 & 0.035 & $1.07[-8.29-10.43]$ & 0.23 & 0.820 & $-5.42[-20.87-10.03]$ & -0.70 & 0.486 \\
\hline \multicolumn{10}{|l|}{ Public/ Church run } \\
\hline Church & \multicolumn{9}{|c|}{ Reference Category } \\
\hline Public & $8.83[-5.64-23.30]$ & 1.22 & 0.227 & $3.07[-1.97-8.10]$ & 1.22 & 0.228 & $0.62[-3.86-5.09]$ & 0.28 & 0.783 \\
\hline \multicolumn{10}{|l|}{ Size of catchment } \\
\hline$>10000$ & \multicolumn{9}{|c|}{ Reference Category } \\
\hline $10000-19999$ & $8.85[-6.71-24.41]$ & 0.55 & 0.260 & $5.67[-0.42-11.75]$ & 1.86 & 0.067 & $7.14[-0.01-14.28]$ & 2.00 & 0.050 \\
\hline $20000-29999$ & $22.17[8.51-35.84]$ & 2.71 & 0.002 & $-0.62[-6.45-5.21]$ & -0.21 & 0.833 & $8.07[-1.21-17.34]$ & 1.74 & 0.087 \\
\hline $30000-49999$ & $2.53[-18.18-19.24]$ & 1.00 & 0.763 & $-0.52[-7.60-6.56]$ & -0.15 & 0.883 & $-4.71[-11.88-2.46]$ & -1.31 & 0.194 \\
\hline$<50000$ & $22.23[-2.03-46.50]$ & 2.04 & 0.072 & $1.51[-5.72-8.74]$ & 0.42 & 0.678 & $-6.86[-15.53-1.80]$ & -1.58 & 0.118 \\
\hline Clinicians employed & $1.14[-7.38-9.95]$ & 0.30 & 0.768 & $2.13[-1.17-5.42]$ & 1.29 & 0.202 & $2.11[-1.41-5.63]$ & 1.20 & 0.236 \\
\hline
\end{tabular}

a. Number of observations: 72; R-squared: 0.3065; Prob>F: 0.0119; RMSE: 23.341

b. Number of observations: 72; R-squared: 0.1354; Prob>F: 0.3914; RMSE: 8.217

c. Number of observations: 72; R-squared: 0.2547; Prob>F: 0.0441; RMSE: 11.805

CI: Confidence Interval; P> |t|: P-value of t-statistic; Prob>F: probability of F statistic; RMSE: Root Mean Square Error; t: t-statistic 


\section{Discussion}

315 This study aimed to explore the service availability and health facility readiness for delivery of 316 antenatal point-of-care HIV and syphilis testing and treatment in PNG. We identified critical

317 gaps in health service availability and health facility readiness. Proximity to a health facility

318 has been shown in the past to be a key determinant of accessing ANC in PNG and other LMICs

$319[46,47]$. Only one province in our study met the global WHO target of two health facilities per

32010000 population. This signals that access to ANC remains a major challenge for PNG and a

321 contributing factor to low antenatal utilization reported in this study and others [46-48].

322 Our findings demonstrated significant shortages of health workers across PNG. Health services

323 rely heavily on nurses, midwives, and CHWs, who make up the majority of the health

324 workforce. There is a need to increase the number of health workers, particularly medical

325 officers, trained in PNG. Approximately 50 medical officers become fully registered

326 practitioners annually [32], with the majority practicing in urban locations. Most, if not all,

327 LMICs face skilled health worker shortages, and also have difficulty educating, training,

328 deploying, and retaining health workers, especially medical officers, in rural areas [49]. This

329 has also been a long-standing challenge for the PNG health system [36, 50]. Many strategies

330 to address health worker deployment and retention have been implemented and evaluated

331 across LMICs including exposing trainees to rural health care during residency [51], financial

332 incentive programs [52], and introducing new levels of health worker cadres, such as HEOs

333 [53]. In PNG, HEOs are a vital component of rural health care, catering for the sparse number

334 of medical officers working in rural areas. HEO training has evolved from a certificate nearly

33520 years ago into a bachelor's degree in health science (rural health) in 2008. However, despite

336 this training program, our results show that health worker deployment and retention in rural

337 areas remains problematic. The government of PNG needs to establish a sustainable program 
targeted toward increasing the number of health workers across all cadres in rural areas to improve service provision $[49,54]$.

340 Globally, average ANC utilization is $83 \%$ [55], the results of this study demonstrate that ANC

341 utilization in PNG is concerningly low and far below the global average. Globally, the barriers

342 to accessing antenatal care are well-documented [56, 57], and include financial, social and

343 cultural constraints [46]; health worker attitudes [58]; or as discussed above, geographical

344 barriers [59]. More recently, greater attention has been paid to patient perceptions of healthcare

345 quality [19, 37, 60-64]. For example, studies have found that women will forego seeking care

346 at their nearest health facility and elect to attend a larger health facility due to concerns

347 regarding quality of care [65]. ANC utilization can be improved through interventions designed

348 to enhance expectant mothers' knowledge and understanding of the importance of ANC [46],

349 patient experience, interactions between ANC attendees and healthcare workers [66, 67], and

350 the quality of ANC [47], and costs of seeking care [68].

351 Health facility readiness was generally low across all health facilities, although urban facilities tended to be better equipped to deliver routine antenatal testing and treatment for HIV and syphilis compared to rural health facilities. Of particular concern was the limited supply of diagnostic tests in rural health facilities compared to urban ones, while limited stock of treatment for HIV and syphilis was a problem across all health facilities sampled. The results indicate ailing health facility infrastructure and poorly equipped health facilities, which are commonly reported in LMICs [20, 69]. These results illustrate the difficulties associated with health facility operations, the quality of service provision, and general health facility maintenance under constrained budgets [70]. Strategies, including year-on-year health facility maintenance, and strengthening procurement and distribution of diagnostics, medicines, and medical supplies, are required to meet the demand for health services in PNG. 
362 The regression results showed that antenatal HIV and/or syphilis testing and treatment were 363 weakly associated with health facility readiness. Factors that had a statistically significant 364 association with testing and treatment were the size of the catchment population and the type 365 of health facility. Specifically, in small catchment populations, and health centres, a greater 366 proportion of antenatal clinic attendees were tested for HIV or syphilis. In absolute values, 367 urban health facilities had higher ANC utilization rates, tested more antenatal clinic attendees for HIV and syphilis, and treated more seropositives compared to rural health facilities. However, this is not the case in relative terms. Therefore, the results were likely due to fewer 370 pregnancies in rural areas compared to urban areas, which are further affected by low ANC 371 utilization rates and late ANC presentation [24, 47, 66, 67].

372 A key strength of our study was the use of two nationally representative datasets that enabled the identification of major variations in readiness scores in 73 health facilities across 19 of PNG's 22 provinces. Further, through data linkage, we were able to explore for the first time, associations between clinical outcomes (testing and treatment for HIV and testing for syphilis) and health facility readiness. Our study also had some limitations. First, health facility readiness provides only a partial view of the quality of antenatal testing and treatment for HIV and syphilis in PNG. However, it is a strong starting point for identifying the inputs necessary to deliver quality antenatal testing and treatment for HIV and syphilis. Second, the association

380 between health facility readiness and the proportion of antenatal clinic attendees treated for syphilis was not included in this analysis. This was because none of the 73 health facilities included in the regression analysis reported any syphilis treatment data in the NHIS. Despite this, we believe that the results presented using the HIV treatment data are indicative of the relationship between health facility readiness and treatment for syphilis. This is due to the similarities in both structure and funding for the national HIV and syphilis programs in PNG $[26,71]$. 
388 The results from this study add to the extremely limited literature on supply side factors

389 affecting the delivery of quality ANC in the Pacific. They highlight a need to improve antenatal

390 testing and treatment coverage for HIV and syphilis, particularly inequalities between rural and

391 urban communities. Shortages in the availability of tests and treatments for HIV and syphilis

392 as well as in skilled health workers, are of particular concern and hinder universal access to

393 quality ANC. Basic amenities such as electricity also need to be improved. There is potential

394 for the PNG health system to increase rates of testing and treatment for HIV and syphilis in

395 pregnancy by improving facility readiness to provide these services. We recommend that future

396 studies investigate the quality of antenatal care delivered at rural and urban facilities in PNG,

397 which would complement the results presented in this study.

\section{Abbreviation List}

400 ANC: Antenatal care; ART: Antiretroviral; CHW: Community health worker; DFAT: 401 Australian Department of Foreign Affairs and Trade; EDD: Expected delivery date; HEO:

402 Health extension officer; HIV: Human immune deficiency virus; KMO: Kaiser-Meyer-Olkin 403 test; LMIC: Low- and middle- income country; MBBS: Bachelor of Medicine and Bachelor of Surgery; NDoH: National Department of Health; NHIS: National Health Indicator Surveillance; PCA: Principal component analysis; PCR: Polymerase chain reaction; PNG:

Papua New Guinea; SARA: Service Availability and Readiness Analysis; SP:

407 Sulfadoxine/pyrimethamine; STI: Sexually transmitted infection; WHO: World Health 408 Organization.

\section{Declarations}

\section{Ethics declarations}


411 This study was granted ethics approval by the PNG Institute of Medical Research Institutional

412 Review Board on the $7^{\text {th }}$ of August 2014 and allocated the approval number: IRB No. 1414.

413 Ethics approval was also granted by the PNG Medical Research Advisory Committee on the

$41410^{\text {th }}$ of August 2014 and allocated the approval number: MRAC No 14.26. This study adheres

415 to the STROBE guidelines for cross-sectional research (see additional file 1). Written consent

416 to collect the data analysed in this study was obtained from provincial and district health

417 authorities, and church health services managing all surveyed health facilities. Prior to data

418 enumeration, oral informed consent was obtained from the officer-in-charge at each of the

419 participating health facilities.

\section{Consent for publication}

421 This manuscript contains no personal data.

\section{Availability of data and materials}

423 The datasets generated and/or analysed during the current study are not publicly available as

424 they contain several identifying variables and openly sharing the data would compromise the 425 privacy of participating health facilities. However, the data are available from the 426 corresponding author on reasonable request.

\section{Competing Interests}

428 The authors declare that they have no competing interests.

\section{Funding sources/ sponsors}

430 The countrywide health facility survey endorsed by the PNG Department of Health and funded

431 by World Bank Trust Fund through the Australian Department of Foreign Affairs and Trade.

432 All authors' affiliated institutions contributed via facilities and/or salary contributions. OPMS

433 is supported by The University of New South Wales Scientia Higher Degree Candidate

434 Scholarship Scheme. All authors' affiliated institutions contributed via facilities and/or salary 
contributions. The funders had no role in study design, data collection and analysis, decision

to publish, or preparation of the manuscript.

\section{Author Contributions}

438 OPMS, NB, AJV and VW conceptualized the study, study design and methodology. OPMS

439 collated the dataset, conducted the analysis, and drafted the manuscript. NB, MK, JP and XH

440 supported data analysis and write-up. WP, AJV and VW critically reviewed the manuscript and

441 approved. All authors have made key intellectual contributions to the development of the 442 manuscript, including editing, and revisions. All authors have read and approved the final 443 manuscript.

\section{Acknowledgement}

445 The authors would like to thank participating health facilities, provincial, government, and 446 church health authorities, and the national department of health. We also acknowledge the PNGIMR for administrative and technical support provided during the initial data collection.

\section{References}

1. Adachi, K., K. Nielsen-Saines, and J.D. Klausner, Chlamydia trachomatis Infection in Pregnancy: The Global Challenge of Preventing Adverse Pregnancy and Infant Outcomes in Sub-Saharan Africa and Asia. Biomed Res Int., 2016. 2016: p. 21.

2. Saleska, J.L., et al., Use of Antiretroviral Therapy During Pregnancy and Adverse Birth Outcomes Among Women Living With HIV-1 in Low- and Middle-Income Countries: A Systematic Review. J Acquir Immune Defic Syndr, 2018. 79(1): p. 1-9.

3. Shava, E., et al., High rates of adverse birth outcomes in HIV and syphilis co-infected women in Botswana. JAIDS Journal of Acquired Immune Deficiency Syndromes, 2019: p. 1.

4. Newman, L., et al., Global Estimates of Syphilis in Pregnancy and Associated Adverse Outcomes: Analysis of Multinational Antenatal Surveillance Data. PLOS Medicine, 2013. 10(2): p. e1001396.

5. Dingens, A.S., et al., Bacterial vaginosis and adverse outcomes among full-term infants: a cohort study. BMC pregnancy and childbirth, 2016. 16(1): p. 278-278.

6. Olaleye, A.O., et al., Sexually transmitted infections in pregnancy - An update on Chlamydia trachomatis and Neisseria gonorrhoeae. European Journal of Obstetrics \& Gynecology and Reproductive Biology, 2020. 255: p. 1-12. 
7. Olson-Chen, C., K. Balaram, and D.N. Hackney, Chlamydia trachomatis and Adverse Pregnancy Outcomes: Meta-analysis of Patients With and Without Infection. Maternal and Child Health Journal, 2018. 22(6): p. 812-821.

8. Konadu, D.G., et al., Prevalence of vulvovaginal candidiasis, bacterial vaginosis and trichomoniasis in pregnant women attending antenatal clinic in the middle belt of Ghana. BMC Pregnancy and Childbirth, 2019. 19(1): p. 341.

9. Gomez, G.B., et al., Untreated maternal syphilis and adverse outcomes of pregnancy: a systematic review and meta-analysis. Bulletin of the World Health Organization, 2013. 91(3): p. 217-226.

10. Vallely, L.M., et al., Adverse pregnancy and neonatal outcomes associated with Neisseria gonorrhoeae: systematic review and meta-analysis. Sexually Transmitted Infections, 2021. 97(2): p. 104-111.

11. Vallely, L.M., et al., Adverse pregnancy and neonatal outcomes associated with Neisseria gonorrhoeae, Mycoplasma genitalium, M. hominis, Ureaplasma urealyticum and U. parvum: a systematic review and meta-analysis protocol. BMJ Open, 2018. 8(11): p. e024175.

12. WHO, WHO recommendation on sexually transmitted infections testing in pregnancy. 2016, WHO: Geneva.

13. WHO Regional Office Western Pacific, Second generation surveillance surveys of HIV, other STIs and risk behaviours in 6 [six] Pacific Island countries. 2006.

14. Vallely, A., et al., The prevalence of sexually transmitted infections in Papua New Guinea: a systematic review and meta-analysis. PloS one, 2010. 5(12): p. e15586e15586.

15. Vallely, A., et al., Point-of-care testing and treatment of sexually transmitted infections to improve birth outcomes in high-burden, low-income settings: Study protocol for a cluster randomized crossover trial (the WANTAIM Trial, Papua New Guinea) [version 1; peer review: awaiting peer review]. Wellcome Open Research, 2019. 4(53).

16. PNG Obstetrics \& Gynaecology Society, Manual of Standard Managements in Obstetrics and Gynaecology for Doctors, HEOs and Nurses in Papua New Guinea. 2016.

17. Severe, L., et al., Rapid-Testing Technology and Systems Improvement for the Elimination of Congenital Syphilis in Haiti: Overcoming the "Technology to Systems Gap". Journal of sexually transmitted diseases, 2013. 2013: p. 247901-247901.

18. Acharya, K., et al., Availability and readiness to provide sexually transmitted infections and HIV testing and counselling services in Nepal: evidence from comprehensive health facility survey. BMJ Open, 2020. 10(12): p. e040918.

19. Lama, T.P., et al., Assessment of facility and health worker readiness to provide quality antenatal, intrapartum and postpartum care in rural Southern Nepal. BMC health services research, 2020. 20(1): p. 16-16.

20. Yadav, H., et al., Availability of essential diagnostics in ten low-income and middleincome countries: results from national health facility surveys. The Lancet Global Health, 2021. 9(11): p. e1553-e1560.

21. Kruk, M.E., et al., High-quality health systems in the Sustainable Development Goals era: time for a revolution. The Lancet Global Health, 2018. 6(11): p. e1196-e1252.

22. Sheffel, A., C. Karp, and A.A. Creanga, Use of Service Provision Assessments and Service Availability and Readiness Assessments for monitoring quality of maternal and newborn health services in low-income and middle-income countries. BMJ global health, 2018. 3(6): p. e001011-e001011. 
23. Tunçalp, Ö., et al., Quality of care for pregnant women and newborns-the WHO vision. BJOG : an international journal of obstetrics and gynaecology, 2015. 122(8): p. 10451049.

24. Razzaq, A., C. Raynes-Greenow, and A. Alam, Barriers to uptaking HIV testing among pregnant women attending antenatal clinics in low- and middle-income countries: A systematic review of qualitative findings. Australian and New Zealand Journal of Obstetrics and Gynaecology, 2021. n/a(n/a).

25. PNG National Department of Health, PNG Health Plan 2011-2020. 2010.

26. PNG National AIDS Council Secretariat, Papua New Guinea National STI and HIV Strategy 2018-2022. 2017, GoPNG: Port Moresby.

27. PNG National Department of Health, Health Information Systems. 2019.

28. Badman, S.G., et al., A novel point-of-care testing strategy for sexually transmitted infections among pregnant women in high-burden settings: results of a feasibility study in Papua New Guinea. BMC infectious diseases, 2016. 16: p. 250-250.

29. PNG National Department of Health, 2018 STI/HIV and AIDS Program Annual Report. 2019: Port Moresby.

30. WHO, Service Availability and Readiness Assessment (SARA): Reference Manual. 2015. 2.2.

31. The World Bank Group. Papua New Guinea Country Indicators. 2020 January 29 2021]; Available from: https://data.worldbank.org/country/papua-new-guinea.

32. Grundy, J., Dakulala, P, Wai, K, Maalsen, A and Whittaker, M, Independent State of Papua New Guinea Health System Review. 2019, World Health Organization. Regional Office for South-East Asia,.

33. WHO and GoPNG, Health Service Delivery Profile: Papua New Guinea, 2012. 2013: Geneva.

34. PNG National Department of Health, Sector Performance Annual Review- Province and District Health Profiles (2018). 2018.

35. PNG National Department of Health, Sector Performance Annual Review (SPAR) Report 2019. 2020.

36. Hou, X.K., M. Mahmud; Pulford, Justin; Saweri, Olga; Demir, Ibrahim; Haider, Rifat; Ahmed, Shakil; Service delivery by health facilities in Papua New Guinea : report based on a countrywide health facility survey (English). . 2018, The WorldBank Group.

37. Leslie, H.H., et al., Service readiness of health facilities in Bangladesh, Haiti, Kenya, Malawi, Namibia, Nepal, Rwanda, Senegal, Uganda and the United Republic of Tanzania. Bulletin of the World Health Organization, 2017. 95(11): p. 738-748.

38. WHO, WHO recommendation on antenatal care for a positive pregnancy experience. 2016: Luxembourg.

39. WHO, Pregnancy, childbirth, postpartum and newborn care: a guide for essential practice. 2015, WHO. p. 184.

40. Kaiser, H.F., An index of factorial simplicity. Psychometrika, 1974. 39(1): p. 31-36.

41. Tabachnick, B.F., L,, Using Multivariate Statistics,. 6th Ed. ed. 2007, : Boston, MA, USA: Pearson Education.

42. Jackson, E.F., et al., Estimation of indices of health service readiness with a principal component analysis of the Tanzania Service Provision Assessment Survey. BMC Health Services Research, 2015. 15(1): p. 536.

43. Henson, R.K. and J.K. Roberts, Use of Exploratory Factor Analysis in Published Research: Common Errors and Some Comment on Improved Practice. Educational and Psychological Measurement, 2006. 66(3): p. 393-416.

44. Bintabara, D., A. Ernest, and B. Mpondo, Health facility service availability and readiness to provide basic emergency obstetric and newborn care in a low-resource 
600

601

602

603

604

605

606

607

608

609

610

611

612

setting: evidence from a Tanzania National Survey. BMJ open, 2019. 9(2): p. e020608e020608.

45. Gage, A.J., O. Ilombu, and A.I. Akinyemi, Service readiness, health facility management practices, and delivery care utilization in five states of Nigeria: a crosssectional analysis. BMC Pregnancy and Childbirth, 2016. 16(1): p. 297.

46. Andrew, E.V.W., et al., Factors Affecting Attendance at and Timing of Formal Antenatal Care: Results from a Qualitative Study in Madang, Papua New Guinea. PLOS ONE, 2014. 9(5): p. e93025.

47. Wilunda, C., et al., Barriers to utilisation of antenatal care services in South Sudan: a qualitative study in Rumbek North County. Reprod Health, 2017. 14(1): p. 65-65.

48. Mueller, I., et al., The effect of distance from home on attendance at a small rural health centre in Papua New Guinea. International Journal of Epidemiology, 1998. 27: p. 878884.

49. WHO, Health workforce requirements for universal health coverage and the Sustainable Development Goals, in Human Resources for Health Observer. 2016.

50. Thomason, J.A. and R.-L. Kolehmainen-Aitken, Distribution and performance of rural health workers in Papua New Guinea. Soc Sci Med, 1991. 32(2): p. 159-165.

51. Matsumoto, M., K. Inoue, and E. Kajii, Policy implications of a financial incentive programme to retain a physician workforce in underserved Japanese rural areas. Social Science \& Medicine, 2010. 71(4): p. 667-671.

52. Bärnighausen, T. and D.E. Bloom, Financial incentives for return of service in underserved areas: a systematic review. BMC Health Services Research, 2009. 9(1): p. 86.

53. WHO, Improving retention of health workers in rural and remote areas: Case studies from the WHO South-East Asia Region. 2020, WHO: New Delhi.

54. Szabo, S., et al., Health workforce demography: a framework to improve understanding of the health workforce and support achievement of the Sustainable Development Goals. Hum Resour Health, 2020. 18(1): p. 7-7.

55. WHO, World Health Statistics 2015. 2015: Geneva.

56. Finlayson, K. and S. Downe, Why do women not use antenatal services in low- and middle-income countries? A meta-synthesis of qualitative studies. PLoS medicine, 2013. 10(1): p. e1001373-e1001373.

57. Miteniece, E., et al., Barriers to accessing adequate maternal care in Central and Eastern European countries: A systematic literature review. Soc Sci Med, 2017. 177: p. 1-8.

58. Mannava, P., et al., Attitudes and behaviours of maternal health care providers in interactions with clients: A systematic review. Global Health, 2015. 11(1): p. 36-36.

59. Kyei-Nimakoh, M., M. Carolan-Olah, and T.V. McCann, Access barriers to obstetric care at health facilities in sub-Saharan Africa-a systematic review. Systematic Reviews, 2017. 6(1): p. 110.

60. Arsenault, C., et al., Equity in antenatal care quality: an analysis of 91 national household surveys. The Lancet Global Health, 2018. 6(11): p. e1186-e1195.

61. Kruk, M.E., et al., Quality of basic maternal care functions in health facilities of five African countries: an analysis of national health system surveys. The Lancet Global Health, 2016. 4(11): p. e845-e855.

62. Gauthier, B. and W. Wane, Bypassing health providers: the quest for better price and quality of health care in Chad. Soc Sci Med, 2011. 73(4): p. 540-549.

63. Rao, K.D. and A. Sheffel, Quality of clinical care and bypassing of primary health centers in India. Soc Sci Med, 2018. 207: p. 80-88. 
64. Macarayan, E.K., et al., Assessment of quality of primary care with facility surveys: a descriptive analysis in ten low-income and middle-income countries. The Lancet. Global health, 2018. 6(11): p. e1176-e1185.

65. McCarthy, E.A., et al., Quality improvement intervention to increase adherence to ART prescription policy at HIV treatment clinics in Lusaka, Zambia: A cluster randomized trial. PLoS One, 2017. 12(4): p. e0175534.

66. Larsen, G.L., et al., Antenatal care in Goroka: issues and perceptions. P N G Med J, 2004. 47(3-4): p. 202-14.

67. Myer, L. and A. Harrison, Why Do Women Seek Antenatal Care Late? Perspectives From Rural South Africa. Journal of Midwifery \& Women's Health, 2003. 48(4): p. 268-272.

68. Mason, L., et al., Barriers and facilitators to antenatal and delivery care in western Kenya: a qualitative study. BMC Pregnancy and Childbirth, 2015. 15(1): p. 26.

69. Kananura, R.M., et al., Persisting demand and supply gap for maternal and newborn care in eastern Uganda: a mixed-method cross-sectional study. Reprod Health, 2017. 14(1): p. 136-136.

70. Mitton, C. and C. Donaldson, Health care priority setting: principles, practice and challenges. Cost Effectiveness and Resource Allocation, 2004. 2(1): p. 3.

71. Machekera, S., et al., Strategic options for syphilis control in Papua New Guineaimpact and cost-effectiveness projections using the syphilis interventions towards elimination (SITE) model. Infectious Disease Modelling, 2021. 6: p. 584-597.

Table 2: Domains and indictors of the supply service readiness for HIV and syphilis testing and treatment

Domain / Indicators Explanation of indicator

Basic Amenities

Electricity

Back-up generator

Fuel for generator

Running water

Toilet

Communication equipment

Emergency transport

Protocols for infection prevention

Sharps final disposal

Final bio-waste disposal
Electricity is available

Back-up power source (generator) available Health facility has fuel to run the generator Running water is available and piped into the health facility At least one functional toilet (can be pit without slab, pit with slab or flushable) available for patients

A functional telephone (landline), shortwave radio or mobile phone is available for communication purposes

A vehicle, not necessarily an ambulance, is available and has the primary function of transporting patients

Protocol in place for final disposal of sharps (e.g., taken of offsite, burnt and/or buried)

Protocol in place for final disposal of bio-waste (e.g., taken offsite, burnt and/or buried) 

bins

\section{Diagnostic equipment}

EDD calculator

Scale

Tape measure

Foetal stethoscope

Blood pressure machine

Refrigerator/Vaccine

carrier

Urinalysis dipsticks and collection cups

Point-of-Care HIV test-kits

Point-of-Care syphilis testkits
Expected date of delivery (EDD) calculator available and able to estimate EDD and gestational age

Available to measure the weight of antenatal clinic attendees Available to measure fundal height (size of uterus) and able to estimate gestational age

Pinard horn is available to check the baby's heart rate Sphygmomanometer is available to measure blood pressure Suitable vaccine carrier available to store/administer vaccines safely

In-stock and available to test urine for protein and glucose to help diagnose pre-eclampsia and gestational diabetes

Serological HIV point-of-care test-kits to test for HIV are available and in-stock (including 30 days prior to survey)

Serological syphilis point-of-care test-kits to test for syphilis are available and in-stock (including 30 days prior to survey)

Medicines and Medical supplies

Gloves

Needles and syringes

Cotton wool

Water for injection

Iron and Folate supplement

Sulfadoxine/pyrimethamine (SP)

Tetanus Toxoid

Benzathine-Penicillin

Antiretroviral

(ART)
Examination gloves are available and in-stock (including 30 days prior to survey)

Needles and syringes are available and in-stock (including 30 days prior to survey)

Cotton wool is available and in-stock (including 30 days prior to survey)

Water for injection, used to reconstitute substances, is available and in-stock (including 30 days prior to survey)

Iron and Folate oral supplement, used to treat anaemia, is available and in-stock (including 30 days prior to survey)

SP, used for intermittent prevention of malaria in pregnancy, is available and in-stock (including 30 days prior to survey)

Tetanus toxoid, used to prevent neonatal tetanus, is available and in-stock (including 30 days prior to survey)

Benzathine-Penicillin, used to treat syphilis, is available and in-stock (including 30 days prior to survey)

therapy ART, used to treat HIV, is available and in-stock (including 30 days prior to survey)

639 Table3: Summary of health facilities $(\mathbf{N}=73)$ and service statistics

Variable
Health facilities

n $(\%)$ 


\begin{tabular}{|c|c|}
\hline Region & \\
\hline Highlands & $21(28.8)$ \\
\hline Momase & $17(23.3)$ \\
\hline New Guinea Islands & $17(23.3)$ \\
\hline Southern & $18(24.7)$ \\
\hline \multicolumn{2}{|l|}{ Health facility type } \\
\hline Hospital & $19(26)$ \\
\hline District/ Rural Hospital & $7(9.6)$ \\
\hline Health Centre & $47(64.4)$ \\
\hline \multicolumn{2}{|l|}{ Location } \\
\hline Urban & $19(26)$ \\
\hline Rural & $54(74)$ \\
\hline \multicolumn{2}{|l|}{ Managing Authority } \\
\hline Public & $47(64.4)$ \\
\hline Church & $26(35.6)$ \\
\hline Population, and service statistics & Average (range) \\
\hline \multicolumn{2}{|c|}{ Pregnant women in catchment population (n) } \\
\hline Urban & $1560(116-14408)$ \\
\hline Rural & $627(36-2273)$ \\
\hline \multicolumn{2}{|c|}{ Pregnant women making at least one antenatal clinic visit (n) } \\
\hline Urban & $1043(64-3206)$ \\
\hline Rural & $295(29-857)$ \\
\hline \multicolumn{2}{|c|}{ Antenatal clinic attendants tested for HIV at sampled health facilities (\%) } \\
\hline Urban & $5.6(0-38.9)$ \\
\hline Rural & $23.5(0-100)$ \\
\hline \multicolumn{2}{|c|}{ HIV seropositive antenatal clinic attendants treated at sampled health facilities (\%) } \\
\hline Urban & $4.2(0-50)$ \\
\hline Rural & $1.1(0-40)$ \\
\hline \multicolumn{2}{|c|}{ Antenatal clinic attendants tested for syphilis at sampled health facilities (\%) } \\
\hline Urban & $11.1(0-81.7)$ \\
\hline Rural & $4.3(0-28.4)$ \\
\hline \multicolumn{2}{|c|}{ Syphilis seropositive antenatal clinic attendants treated at sampled health facilities (\%) } \\
\hline Urban & No data \\
\hline Rural & No data \\
\hline
\end{tabular}




\section{Supplementary Files}

This is a list of supplementary files associated with this preprint. Click to download.

- SaweriAdditionalFileSTROBEguidelines.docx 